Article

\title{
Highly Hydrophobic Cotton Fabrics Modified by Poly(methylhydrogen)siloxane and Fluorinated Olefin: Characterization and Applications
}

\author{
Huiping Lin ${ }^{1,+}$, Qingjian Hu ${ }^{1,+}$, Tianyu Liao ${ }^{1}$, Xinxiang Zhang ${ }^{1} \mathbb{D}$, Wenbin Yang ${ }^{1, *}$ and \\ Shuang Cai ${ }^{2, *}$ \\ 1 College of Materials Engineering, Fujian Agriculture and Forestry University, Fuzhou 350108, China; \\ 18450077642@163.com (H.L.); hqj0215@163.com (Q.H.); lty1214745470@163.com (T.L.); \\ xxzhang0106@163.com (X.Z.) \\ 2 College of Chemical Engineering, Hubei University of Arts and Science, Xiangyang 441053, China \\ * Correspondence: fafuywb@163.com (W.Y.); shuangcai@hbuas.edu.cn (S.C.) \\ + These authors contribute to this work equally.
}

Received: 26 February 2020; Accepted: 3 April 2020; Published: 6 April 2020

\begin{abstract}
Highly hydrophobic cotton fabrics were obtained with poly(methylhydrogen)siloxane (PMHS) and a further fluorinated olefin modification. The chemical structures and microstructures of PMHS-modified cotton fabrics were characterized, and application of the resultant cotton fabrics in stain resistance and oil-water separation was demonstrated. PMHS chains with very low surface energy were grafted onto cotton fabric by the dehydrogenation reaction between -Si-H of PMHS and -OH groups of cotton fabric at room temperature. The water contact angle of PMHS-modified cotton fabric was $141.7^{\circ}$, which provided the modified cotton fabric with good stain resistance to waterborne pollutants. The separation efficiency of diesel from water was higher than $92 \%$ for 20 repeatable separation cycles. A further improvement in stain resistance to oil was also demonstrated by a further addition reaction of $1 \mathrm{H}, 1 \mathrm{H}, 2 \mathrm{H}$-perfluoro-1-decene with PMHS-modified cotton fabric.
\end{abstract}

Keywords: cotton fabric; hydrophobic; poly(methylhydrogen)siloxane; fluorinated olefin; oil-water separation

\section{Introduction}

Cotton fabrics are widely applied as textiles because they are soft, comfortable, breathable, and do not irritate human skin [1]. Moreover, they are also used as absorbent materials due to cotton's microscale porous structure [2]. However, cotton fabrics possess two arresting disadvantages: unsatisfactory stain resistance to liquids and poor selectivity in liquid absorption [3]. Normal cotton fabrics can be easily stained by juice, pigment, and blood, and they are unable to selectively separate oils from the oil/water mixture. Therefore, it is highly desirable to improve the stain resistance of cotton fabrics and afford them unique oil/water separation ability.

Fabricating a superhydrophobic surface on cotton fabrics has been extensively studied, which has been demonstrated as an effective method in the functionalization of cotton fabrics for self-cleaning [4,5] and oil/water separation [6-10]. The superhydrophobic surface on cotton fabrics could be realized by various techniques, including the CVD (chemical vapor deposition) method [11-13], sol-gel process [3,14,15], solution immersion [16,17], spray deposition [18-20], and graft polymerization [1,12,21-25]. Two essential factors for the fabrication of a superhydrophobic surface on cotton fabrics are (i) rough surface and (ii) low surface energy. To build a rough surface on cotton fabrics, inorganic nanoparticles such as $\mathrm{ZnO}[26], \mathrm{TiO}_{2}[6,7,15,27]$, and $\mathrm{SiO}_{2}$ [2,14,28] were employed. Since the inorganic nanoparticles were generally very hydrophilic, a further 
hydrophobic modification process should be carried out to lower the surface energy of the resultant rough surface. The modifiers could be classified as stearic acid [29], n-octadecylthiol [30], chlorosilane (octadecyltrichlorosilane [31]), siloxane $\left(\mathrm{R} \prime \mathrm{Si}(\mathrm{OR})_{3}, \mathrm{R}=-\mathrm{CH}_{3},-\mathrm{CH}_{2} \mathrm{CH}_{3} ; \mathrm{R}^{\prime}=-\left(\mathrm{CH}_{2}\right)_{\mathrm{n}} \mathrm{CH}_{3}\right.$, or $\left.-\mathrm{CH}_{2} \mathrm{CH}_{2}\left(\mathrm{CF}_{2}\right)_{n} \mathrm{CF}_{3}\right)$ [11,32-36], or polyhedral oligomeric silsesquioxane (POSS) [37-39]. Among them, fluorine-containing compounds, which are characterized by long fluoroalkyl chains of $\mathrm{C} 8$ or higher [35,36,40-42], have most commonly been utilized owing to the ultra-low surface energy.

To date, the fabrication of a superhydrophobic surface on cotton fabrics has been extensively investigated. However, when taking practical applications into account, the reported approaches possess several disadvantages. First, fluorinated compounds are expensive [43]. Second, hierarchical structures fabricated on cotton fabrics possess poor stability because they commonly consist of inorganic nanoparticles, which were randomly stacked on the cotton fabrics. The bonding among the inorganic nanoparticles is quite poor. Although many works have attempted to improve the bonding of nanoparticles to cotton fabrics and also the bonding between individual nanoparticles by organic materials (such as polymers) [5], the organic/inorganic hybrid coatings on cotton fabrics cannot be thin enough to keep the original appearance (especially for colored cotton fabrics), softness, and wearing comfort of pristine cotton fabrics [1]. Third, most of the methods for the fabrication of superhydrophobic surfaces on cotton fabrics are too complicated to be used practically.

Cotton fabrics possess inherent surface roughness on the microscale due to the textural structure and complicated weave pattern [39]. Therefore, highly hydrophobic cotton fabrics can be realized by a one-step hydrophobic modification of cotton fabrics with hydrophobic materials with very low surface energy [1,44]. In practical application, superhydrophobicity is not a necessary condition for the stain resistance and oil/water separation of cotton fabrics, and a highly hydrophobic property is enough. Actually, for application in stain resistance and oil/water separation, highly hydrophobic cotton fabrics modified by fluorine-free materials can overcome the aforementioned disadvantages of superhydrophobic cotton fabrics.

The aim of this work is to fabricate highly hydrophobic cotton fabrics by the covalent grafting of poly(methylhydrogen)siloxane (PMHS) and a further addition of fluorinated olefin $(1 \mathrm{H}, 1 \mathrm{H}, 2 \mathrm{H}-$ perfluoro-1-decene). In consideration of the molecular structure, PMHS contains amounts of $-\mathrm{Si}-\mathrm{H}$ groups and $-\mathrm{CH}_{3}$ groups $[45,46]$. The former groups can react with the hydroxyl groups of cotton fabrics, and the latter groups afford PMHS chains very low surface energy. Therefore, PMHS was used to functionalize the cellulose-based substrates for water repellence and oil-water separation [47,48]. In this work, after modification, hydrophobic PMHS chains can be covalently bonded onto the cotton fabrics. PMHS is transparent [49] and PMHS chains possess good flexibility [50]; therefore, PMHS modification will probably not affect the original appearance, softness, and wearing comfort of cotton fabrics. To further improve the resistance of cotton fabric to oil, a further addition reaction was applied to modify PMHS-modified cotton fabric with $1 \mathrm{H}, 1 \mathrm{H}, 2 \mathrm{H}$-perfluoro-1-decene. Pristine and modified cotton fabrics were characterized systematically, and their application in stain resistance and oil/water separation was well demonstrated.

\section{Experimental Sections}

\subsection{Materials}

PMHS with a molecular weight of about 1600 and a content of active hydrogen (Si-H) of $1.5 \%$ and Karstedt catalyst (platinum-1,3-divinyl-1,1,3,3-tetramethyldisiloxane) with a Pt content of 2000 ppm were purchased from the Chenguang Research Institute of Chemical Industry (Chengdu, China). $1 \mathrm{H}, 1 \mathrm{H}, 2 \mathrm{H}-$-Perfluoro-1-decene, hexane, and methylene blue (MB) were obtained from ALADDIN Reagent Co., Ltd (Shanghai, China). The cotton fabrics were obtained from a local fabric store ( 60 ends $/ \mathrm{cm}, 30$ picks $/ \mathrm{cm}, 0.42 \mathrm{~mm}$ thickness, $120 \mathrm{~g} / \mathrm{m}^{2}$ weight, and $35.2 \mathrm{~m}^{2} / \mathrm{g}$ specific surface area). 


\subsection{Surface Modification of Cotton Fabrics}

\subsubsection{PMHS Modification}

The modifier solutions with various PMHS concentration of $0.05 \mathrm{wt} \%, 0.10 \mathrm{wt} \%, 0.50 \mathrm{wt} \%$, $1.00 \mathrm{wt} \%, 5.00 \mathrm{wt} \%, 10.00 \mathrm{wt} \%$, and $20.00 \mathrm{wt} \%$, respectively, were obtained by magnetic stirring of PMHS, $50 \mathrm{~mL}$ hexane, and 3 drops of Karstedt catalyst (about $0.15 \mathrm{~mL}$ ) at room temperature for about $5 \mathrm{~min}$. The hydrophobic modification of cotton fabrics was carried out by a very simple process. Before PMHS modification, cotton samples $(4.0 \mathrm{~cm} \times 4.0 \mathrm{~cm})$ were ultrasonically rinsed several times with ethanol and deionized water and then dried at $100{ }^{\circ} \mathrm{C}$ for $6 \mathrm{~h}$. Then, the cotton fabrics were immersed into the modifier solutions at room temperature for about $5 \mathrm{~min}$ and then withdrawn and maintained at room temperature for the evaporation of hexane. During modification, PMHS reacts with $\mathrm{OH}$ groups of cellulose, resulting in a covalent linkage of hydrophobic PMHS chains onto cotton fabrics (Scheme 1).

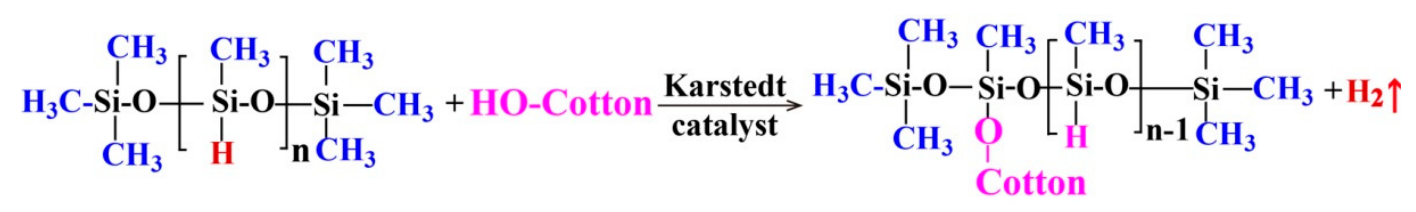

Scheme 1. Reaction of poly(methylhydrogen)siloxane (PMHS) with cotton fabric.

\subsubsection{Fluorinated Olefin Modification}

Cotton fabric modified by a modifier solution with a PMHS concentration of $10.0 \%$ was further modified by immersing into the $5 \mathrm{wt} \% 1 \mathrm{H}, 1 \mathrm{H}, 2 \mathrm{H}-$ perfluoro-1-decene/hexane solution for $5 \mathrm{~min}$ at room temperature and then withdrawing and maintaining it at room temperature for the evaporation of hexane. To accelerate the evaporation of hexane, the modified fabric can be heated at $60^{\circ} \mathrm{C}$ for $1 \mathrm{~h}$. During modification, an addition reaction occurred between the vinyl groups of $1 \mathrm{H}, 1 \mathrm{H}, 2 \mathrm{H}$-perfluoro-1-decene and the residual -Si-H groups of the PMHS-modified cotton fabric, and therefore, long fluoroalkyl chains with ultra-low surface energy were grafted onto the surface of the cotton fabric (Scheme 2).

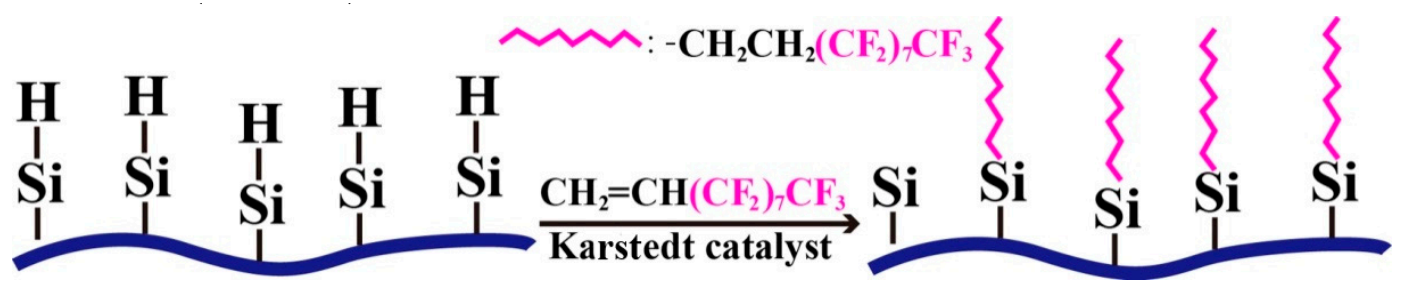

Scheme 2. Reaction of PMHS-modified cotton fabric with 1H,1H,2H-perfluoro-1-decene.

\subsection{Characterization}

Infrared absorption spectra of pristine and PMHS-modified cotton fabrics were analyzed by FTIR (Fourier transform infrared spectroscopy) (Bruker Tensor 27, Bruker Optik, Ettlingen, Germany) using the attenuated total reflectance (ATR) method (ranging from 4000 to $400 \mathrm{~cm}^{-1}, 32$ scans, resolution of $0.1 \mathrm{~cm}^{-1}$ ). For the ATR method, it is very important to obtain good contact between the crystal and the cotton fabrics, which was achieved by pressing the cotton fabrics down on the ZnSe crystal. The XPS (X-ray photoelectron spectroscopy) spectra of the samples were obtained by using a Thermo SCIENTIFIC ESCALAB 250Xi (Thermo Fisher Scientific, Pittsburgh, PA, USA) with Al X-radiation (K $\alpha$, $\mathrm{h} v=1486.8 \mathrm{eV}$ ). Two different spots (spot size $=400 \mu \mathrm{m}$ ) were analyzed per sample at take-off angle $90^{\circ}$. The power was $150 \mathrm{~W}(15 \mathrm{kV}$ and $10 \mathrm{~mA})$, and the vacuum of the sample chamber was $2 \times 10^{-9} \mathrm{mbar}$. The survey spectra were acquired with a pass energy and resolution of $30 \mathrm{eV}$ and $1 \mathrm{eV}$, respectively. 
An electron flood gun was used to compensate for the charges on the surface. Note that the samples for FTIR and XPS characterization were washed with hexane three times to remove PMHS, which did not react with the cotton fabrics. For the test of water contact angle (WCA) values, rectangular samples $\left(40 \times 20 \mathrm{~mm}^{2}\right)$ of the cotton fabrics were cut and pasted onto glass slide with double-face tape. The WCA of cotton fabric was measured on a commercial contact angle meter (HARKE-SPCA-1, Beijing, China) at room temperature with $5 \mu \mathrm{L}$ water droplets. The surface morphology and microstructure of the cotton fabrics were characterized using a scanning electron microscope (SEM, Z500, ZEISS, Jena, Germany) operating at an acceleration voltage of $20 \mathrm{kV}$ in combination with energy-dispersive $X$-ray spectroscopy (EDS, Genesis, EDAX Inc., Mahwah, NJ, USA). Before characterization, the samples were coated with a layer of platinum. 3. Results and Discussion

\section{Results and Discussion}

\subsection{Chemical Structure Analysis}

The modification of cotton fabrics by PMHS is based on the dehydrogenation reaction between the $-\mathrm{Si}-\mathrm{H}$ groups of PMHS and the $-\mathrm{OH}$ groups of cotton fabrics. Figure 1 shows the FTIR-ATR spectra of pristine and PMHS-modified cotton fabrics. For the pristine cotton, absorption bands at $2916 \mathrm{~cm}^{-1}$ were attributed to the $-\mathrm{CH}$ asymmetric and symmetric stretching vibrations of methylene groups of cellulose [51]. Absorption bands at 1161, 1108, 1056, and $1032 \mathrm{~cm}^{-1}$ were attributed to $\mathrm{C}-\mathrm{O}-\mathrm{C}$ vibrations in the cellulose intra- and intermolecular structure [51,52]. For PMHS-modified cotton fabric, the grafting of PMHS chains on cotton fabrics is demonstrated by the appearance of bands from $2965,1260,835$, and $765 \mathrm{~cm}^{-1}$ that correspond to the vibration of the $\mathrm{Si}_{-} \mathrm{CH}_{3}$ group [53-57] of the PMHS chain and by an absorption band located at $2165 \mathrm{~cm}^{-1}$ that corresponds to the Si-H asymmetric stretch mode of the PMHS chain [58]. The obvious appearance of an -Si-H absorption band was attributed to the steric effect of plentiful $-\mathrm{CH}_{3}$ groups on the PMHS chains. In addition, the dehydrogenation reaction between PMHS and cotton fabrics is also proven by the significant decrease in the $-\mathrm{OH}$ absorption band at $3337 \mathrm{~cm}^{-1}$ [59]. Since the samples for FTIR characterization have been washed by hexane three times, it can be concluded that the PMHS chains were covalently grafted onto the cotton fabrics.

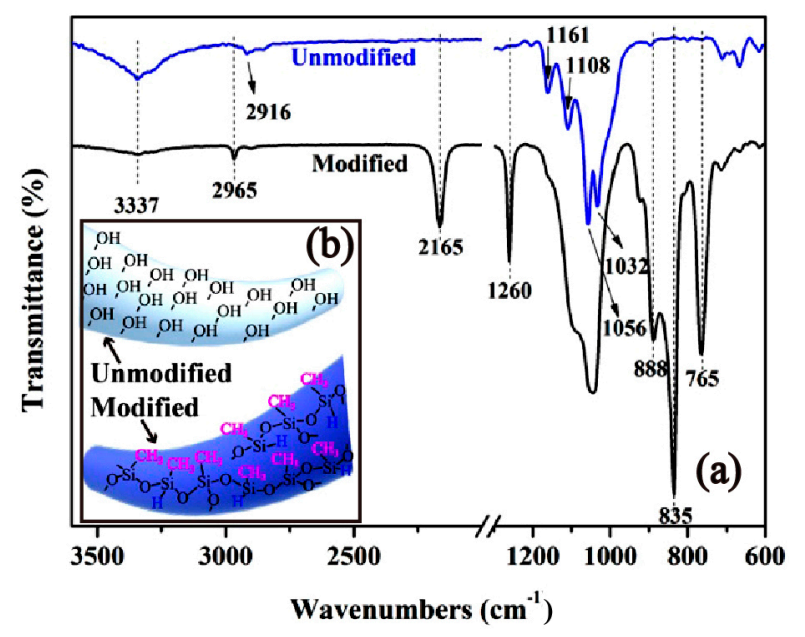

Figure 1. The Fourier transform infrared spectroscopy (FTIR) spectra (a) and schematic representation (b) of pristine and PMHS-modified cotton fabric. Modified cotton fabric was modified by modifier solution with a PMHS concentration of $1.00 \%$ and then washed with hexane three times.

As shown in Figure 2, XPS spectra show the composition changes of cotton fabrics before and after modification. As shown in Figure 2a, C, O, and very few Si elements were detected at the binding energy of $284.8,531.4$, and $102.0 \mathrm{eV}$ on the surface of pristine cotton fabrics [60,61]. As shown in 
Figure $2 \mathrm{~b}$, Si content was significantly increased from $4.0 \%$ to $32.0 \%$, while $\mathrm{C}$ and $\mathrm{O}$ content decreased obviously from $69.1 \%$ and $26.9 \%$ to $35.2 \%$ and 32.85 , respectively. This is in good agreement with the results of FTIR, in which PMHS chains were concluded to be grafted onto the surface of the cotton fabric. As shown in the inserted image in Figure 1b, after PMHS modification, there is probably a layer of PMHS fabricated on the cotton fabric, and therefore the XPS spectrum of PMHS-modified fabric will be similar to that of PMHS, whose C/O/Si atomic ratio is about 1:1:1.
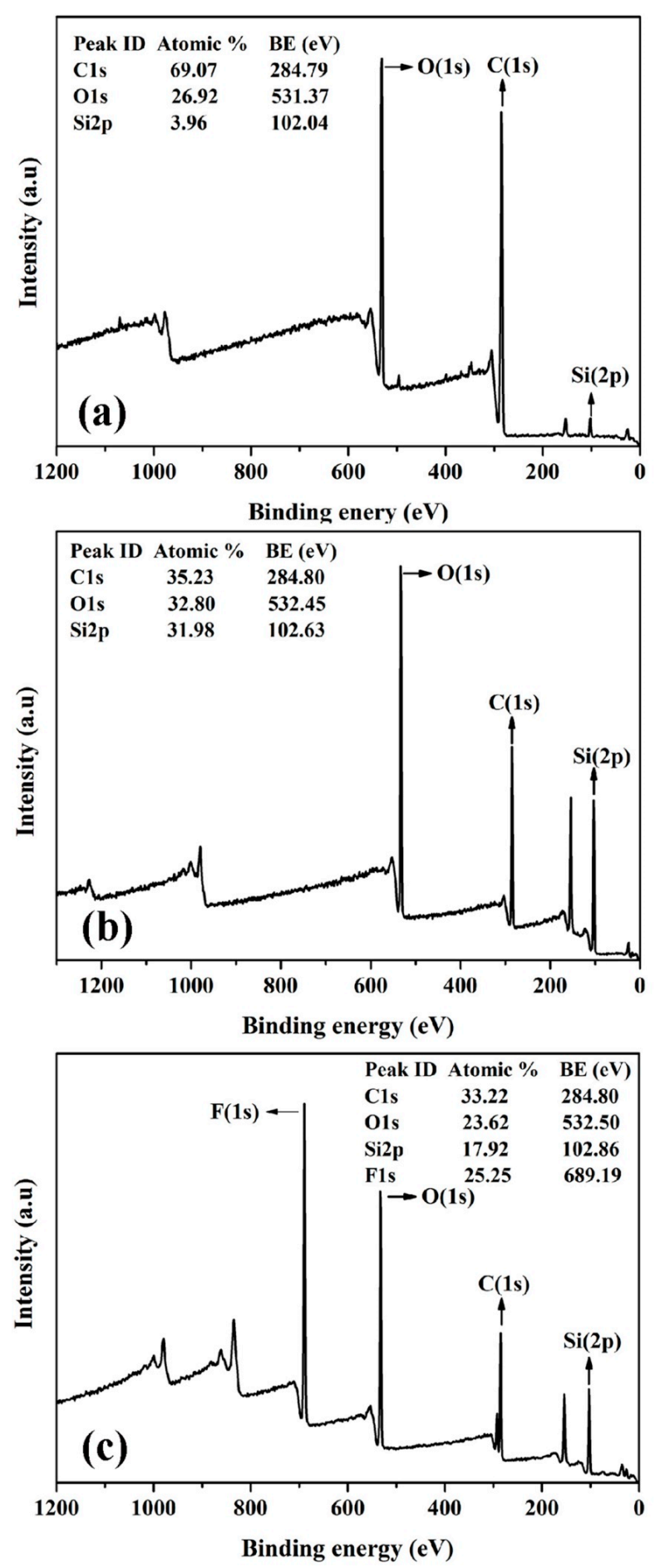

Figure 2. XPS survey spectra of pristine cotton fabric (a), PMHS-modified cotton fabric (b), and fluorinated olefin-modified cotton fabrics (c). 


\subsection{Microstructure Characterization}

Figure 3a,b,d,e show the SEM images of pristine cotton fabric and PMHS-modified cotton fabric. At low magnification, SEM images (Figure 3a,d) indicated that no significant morphology change was found between the unmodified and PMHS-modified cotton fabrics. This is because there is only a thin PMHS layer formed on surface of the cotton fabric. However, at higher magnification, some delicate differences were observed as shown in Figure 3b,e. The gaps between adjacent fibers in unmodified cotton fabric were clear, but they were replaced by PMHS for the modified cotton fabric. As at higher magnification, the surface of PMHS-modified fibers was smoother due to the covering of the PMHS layer.
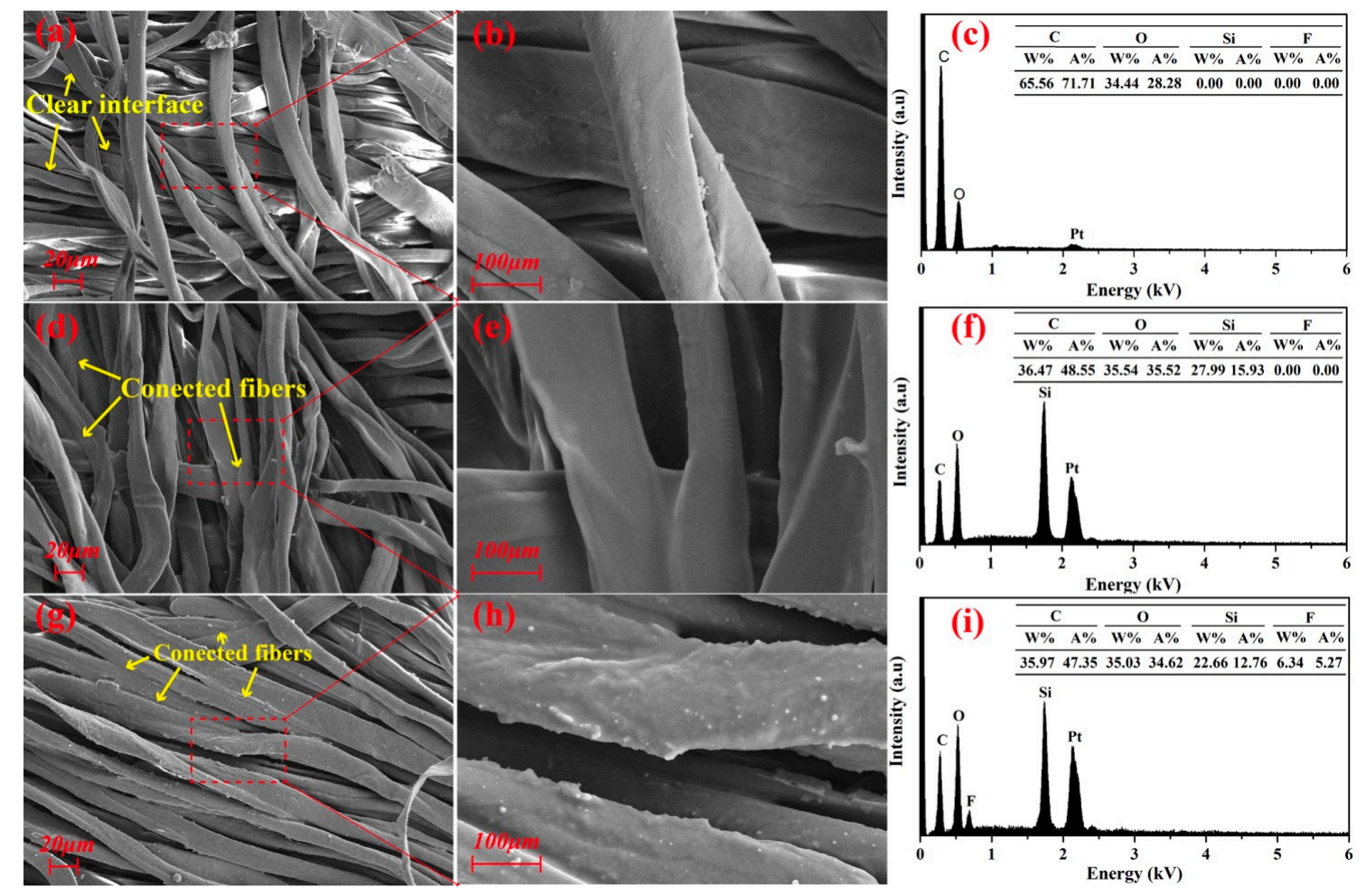

Figure 3. SEM images of pristine (a,b), PMHS-modified (d,e), and fluorinated olefin-modified $(\mathbf{g}, \mathbf{h})$ cotton fabrics and corresponding EDX (energy-dispersive X-ray spectroscopy) spectra $(\mathbf{c}, \mathbf{f}, \mathbf{i})$.

\subsection{Hydrophobicity and Water Resistance}

Figure 4 shows the effect of PMHS concentration in modifier solution on the water contact angle and water absorption of cotton fabrics. As shown in Figure $4 b, c$, the water droplets are difficult to be placed on the surface of cotton fabrics because they are highly hydrophobic. It is hard to record their WCA values. In this work, the WCA was tested with the needle inserted into the water droplet. It can be deduced that the recorded WCA values will be smaller than the actual values. In addition, the measurement of WCA was experienced because the estimation of the baseline for the determination of the WCA is much harder due to the existence of protruding fibers in the woven structure [62,63]. Regardless of these, as shown in Figure 4, it can be seen that PMHS modification significantly improves the hydrophobicity of cotton fabrics. For the pristine fabric, the water droplet was absorbed quickly due to the very hydrophilic property of cellulose and wicking of water, and therefore, its WCA value is about $0^{\circ}$. The PMHS concentration of the modifier solution has little effect on the WCA value. This is probably because of the fast fabrication of the PMHS layer onto the cotton fabric. One of the advantages of our modifier method is that the grafting of PMHS chains can be accomplished very fast at room temperature. With Karstedt catalyst, the dehydrogenation between 
-Si-H of PMHS and -OH of cellulose is ultra-fast. Therefore, as soon as the cotton fabric was immerged into the modifier solution, a thin PMHS layer was formed on its surface. The sliding angles of the water droplets on PMHS-modified cotton fabrics were also tested, which were all lower than $10^{\circ}$. This is also demonstrated vividly in Video S1, in which the water droplets (dyed by MB) immediately rolled of the $10 \%$ PMHS-modified cotton fabric easily. Therefore, in this work, it is difficult to conclude that PMHS-modified cotton fabrics were superhydrophobic, because the static WCA was tested to be lowered than $150^{\circ}$. It is well known that PMHS possesses very low surface energy, and hence the covalent graft of PMHS on will stop cotton fabric absorbing water from water. Water absorption was applied to reveal the hygroscopicity of cotton fabric, which was calculated as follows:

$$
\text { Water absorption }=\frac{m_{1}-m_{0}}{m_{0}}
$$

where $m_{0}$ and $m_{1}$ were the mass of cotton fabrics before and after water immersion for $24 \mathrm{~h}$. As shown in Figure 4, the water absorption of unmodified cotton fabric is higher than $170 \%$, while those of the modified ones are obviously decreased to about $30 \%$, indicating good water resistance for the modified cotton fabrics. As shown in Figure 4d, the unmodified cotton fabric immediately absorbed water and sank into the water. However, for the modified one, it floated on the water surface because it cannot be wetted. After being forcibly immersed into water, a mirror-like surface was observed on the cotton fabric, owing to the reflection of light by the air bubbles trapped on the surface of the cotton fabric [28]. Furthermore, PMHS concentration has little effect on the wettability of modified cotton fabrics. This is because PMHS is of very low surface energy, and the dehydrogenation between -Si-H of PMHS and -OH of cellulose in cotton fabric is ultra-fast [58]. Therefore, a very hydrophobic PMHS layer will form on the surface of cotton fabrics as they were immersed into PMHS modifier solutions.
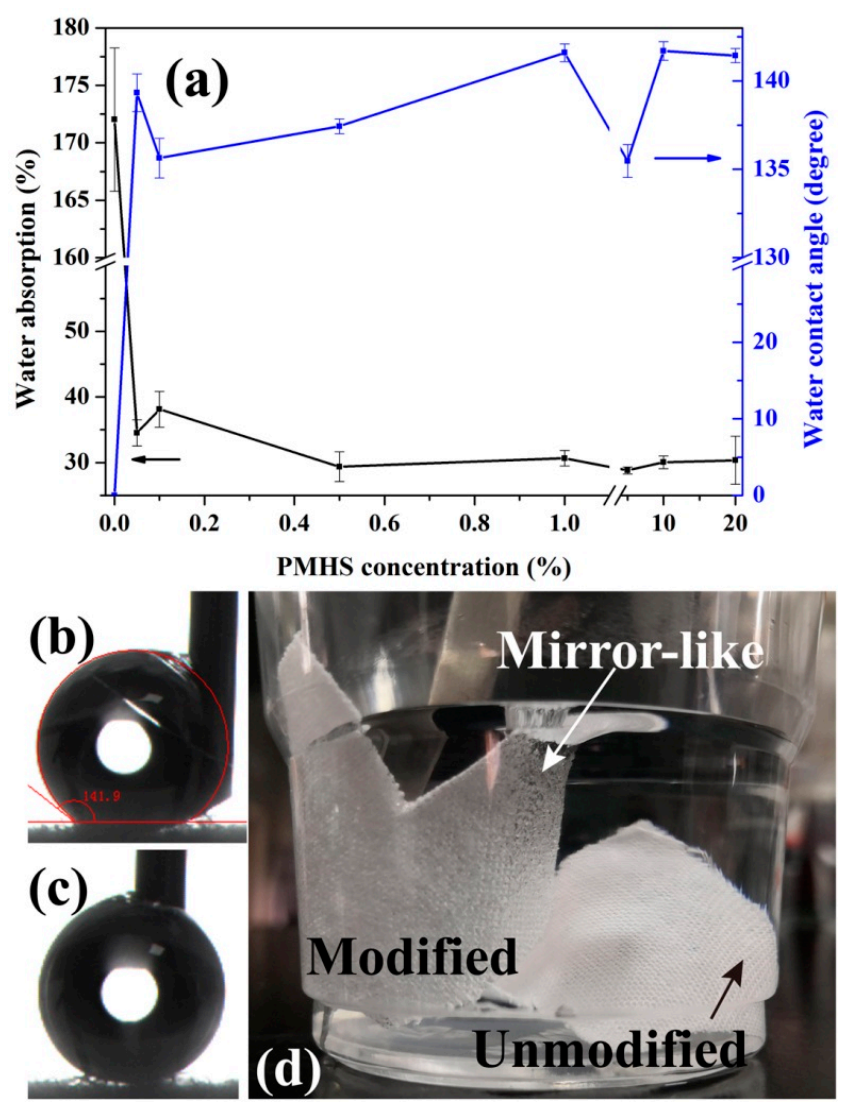

Figure 4. Change in water absorption and water contact angle as a function of PMHS concentration (a), pictures of the water contact angle (WCA) test process $(\mathbf{b}, \mathbf{c})$ and cotton fabrics immersed in water $(\mathbf{d})$. 


\subsection{Application in Stain-Resistance}

In order to demonstrate the stain resistance of PMHS-modified cotton fabric to waterborne pollutants, aqueous MB droplets were dripped onto the surface of cotton fabrics. As shown in Figure 5a, the MB droplets spread easily on the surface of pristine cotton fabrics, and a distinct mark was observed after absorbing aqueous MB droplets by a tissue. This indicated that the pristine cotton fabric possessed poor stain resistance. As shown in Figure $5 b-h$, the modification of cotton fabric with PMHS significantly improved the water repellence, as the aqueous MB droplets displayed good spherical shapes. Since aqueous MB droplets could not spread on the surface of PMHS-modified cotton fabrics, there were inconspicuous marks on surface of the cotton fabrics modified by modifier solutions with PMHS concentration lower than 1\%. At the PMHS concentration higher than 5\%, no macroscopic mark was observed. Moreover, as shown in Video S1 (Supplementary Materials), the water droplets (dyed by MB) immediately rolled of the 10\% PMHS-modified cotton fabric easily. This demonstrated convincingly that PMHS-modified cotton fabrics possessed good stain resistance to waterborne pollutants.
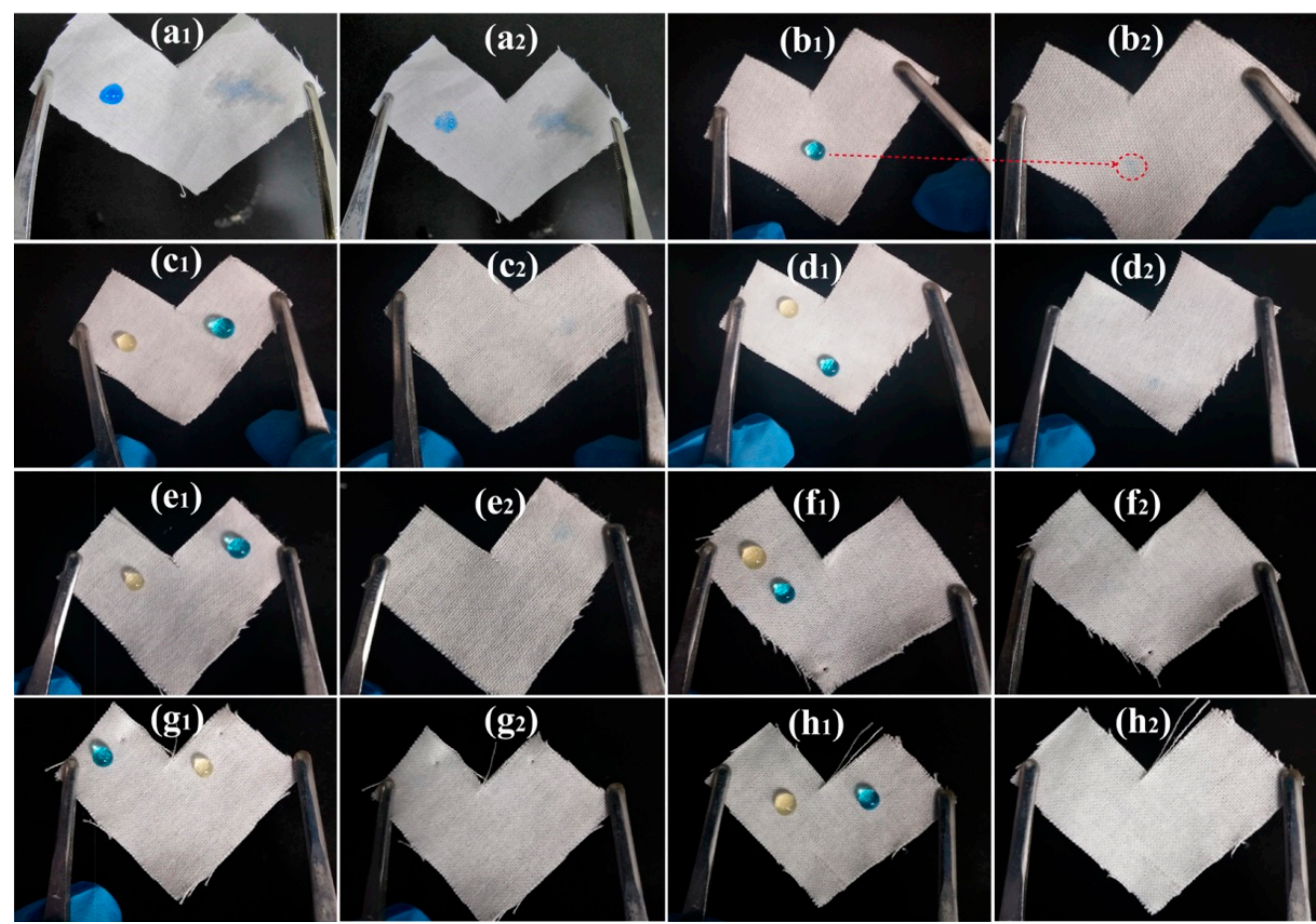

Figure 5. Stain resistance of cotton fabrics to orange juice and aqueous MB droplets: pristine cotton fabric (a), cotton fabrics modified by modifier solution with PMHS concentration of $0.05 \%$ (b), $0.10 \%$ (c), $0.50 \%(\mathbf{d}), 1.00 \%(\mathbf{e}), 5.00 \%(\mathbf{f}), 10.00 \%(\mathrm{~g})$, and $20.00 \%(\mathbf{h}) ; \mathrm{x} 1$ and $\mathrm{x} 2$ are photographs before and after absorbing droplets from the cotton surface $(x=a, b, c, d, e, f, g$ or $h)$.

In addition to stain resistance to waterborne pollutants, PMHS-modified cotton fabrics can gain stain resistance to oil by a further addition reaction with $1 \mathrm{H}, 1 \mathrm{H}, 2 \mathrm{H}$-perfluoro-1-decene. As shown in the FTIR spectra (Figure 1), there was a significant absorption band at $2165 \mathrm{~cm}^{-1}$ for PMHS-modified cotton, indicating that PMHS-modified cotton fabric was rich in -Si-H bonds. With Karstedt catalyst, the addition reaction between - $\mathrm{Si}-\mathrm{H}$ of PMHS-modified cotton fabric and vinyl groups of $1 \mathrm{H}, 1 \mathrm{H}, 2 \mathrm{H}$-perfluoro-1-decene occurs easily at room temperature, and therefore, the long fluoroalkyl chains can be grafted onto the cotton fabrics by a simple immerging method. As shown in XPS spectra (Figure 2e), there was an addition peak at $689.19 \mathrm{eV}$ attributed to the F element [64]. As shown in Figure 6, as the oil droplet (about $0.05 \mathrm{~mL}$ ) was dripped onto pristine cotton fabric, the oil spread easily, and quite a big area of cotton fabric was stained by oil. PMHS modification of cotton fabric 
had no benefit regarding the stain resistance of cotton fabric to oil, as the oil droplet also spread quickly on surface of the PMHS-modified cotton fabric. This is because PMHS chains were abundant in $-\mathrm{CH}_{3}$ groups, which leads to an oleophilic characteristic for PMHS-modified cotton fabric. Long fluoroalkyl chains are well known for their ultra-low surface energy and oil resistance. As shown in Figure 6c, the oil droplet was stable, and no spread was observed on $1 \mathrm{H}, 1 \mathrm{H}, 2 \mathrm{H}$-perfluoro-1-decene-modified cotton fabric. This provides an idea for the preparation of cotton fabric with stain resistance to both water and oil, and systematic research can be carried out based on this work.

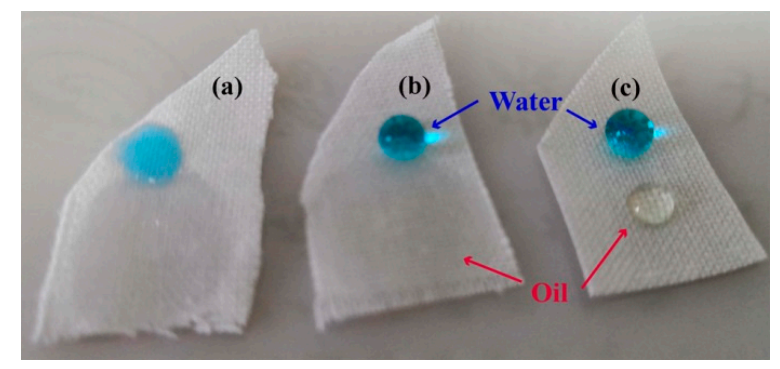

Figure 6. Oil droplet on pristine (a), PMHS-modified (b) and 1H,1H,2H-perfluoro-1-decene-modified (c) cotton fabrics.

\subsection{Application in Oil-Water Separation}

The application of PMHS-modified cotton fabric in oil-water separation was also demonstrated. As shown in Figure 7, because the density of diesel was smaller than water, the separation apparatus should be tilted. To determine the separation efficiency, $10 \mathrm{~mL}$ of diesel and $10 \mathrm{~mL}$ of water were mixed and poured into the separation apparatus continuously. As shown in Figure $7 \mathrm{~b}$, the highly hydrophobic cotton fabrics can only absorb diesel but repel water, and as a result, only diesel flowed through the cotton fabrics and fell down to the conical flask. Figure 7a shows the change in separation efficiency as a function of separation cycles. After 20 repeatable separation cycles, the separation efficiency of diesel from water was demonstrated to be higher than $92 \%$. This indicated good oil-water separation ability and a good recyclability of PMHS-modified cotton fabrics.
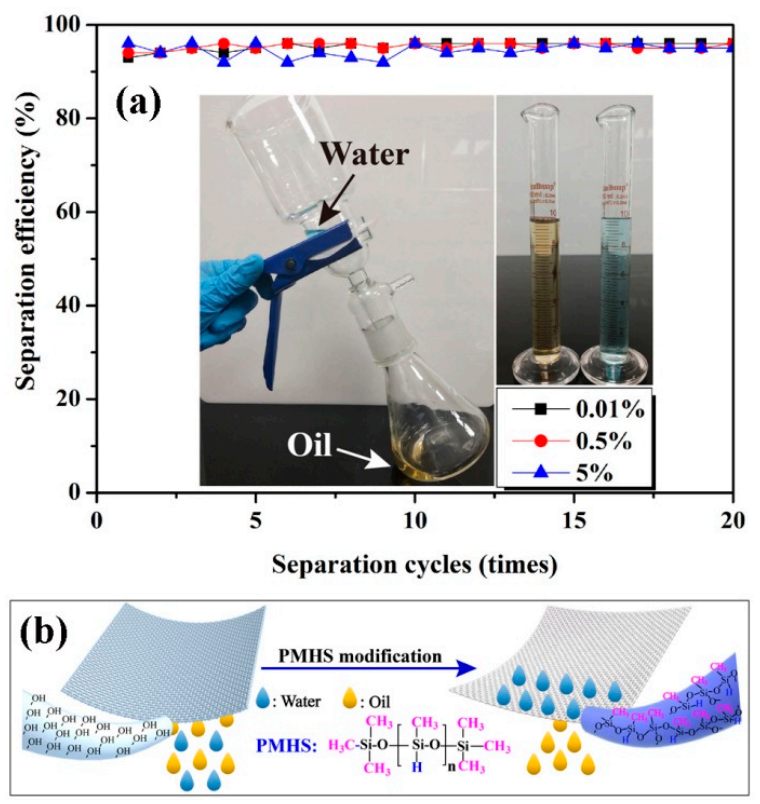

Figure 7. (a) Change in separation efficiency of diesel from water as a function of separation cycles (cotton fabrics were modified by modifier solution with PMHS concentrations of $0.01 \%, 0.5 \%$, and $5 \%$ ); (b) Chematical representation of oil/water seperation of PMHS-modified cotton fabric. 


\section{Conclusions}

In summary, highly hydrophobic cotton fabrics were fabric by PMHS modification. PMHS chains with very low surface energy were covalently bonded to the surface of cotton fabrics. PMHS modification did not significantly affect the microstructure of cotton fabric. After PMHS modification, the water contact angle of cotton fabric was significantly improved to $141.7^{\circ}$. Excellent water repellence afforded the resultant cotton fabric good stain resistance to waterborne pollutants. PMH-modified cotton fabrics also possessed good oil-water separation ability, with the separation efficiency higher than 92\%. PMHS-modified cotton fabrics are abundant in -Si-H groups, and a further improvement in stain resistance to oil was also demonstrated by an additional reaction with $1 \mathrm{H}, 1 \mathrm{H}, 2 \mathrm{H}$-perfluoro-1-decene.

Supplementary Materials: The following are available online at http://www.mdpi.com/2073-4360/12/4/833/s1, Video S1: Water-repellence of PMHS modified cotton fabric.

Author Contributions: Conceptualization, X.Z. and W.Y.; Data curation, H.L. and Q.H.; Formal Analysis, Q.H. and T.L.; Writing-Original Draft, H.L. and X.Z.; Writing—Review \& Editing, W.Y. and S.C. All authors have read and agreed to the published version of the manuscript.

Acknowledgments: The authors gratefully acknowledge the support from the Foundation of Educational Commission of Hubei Province (Q20192602).

Conflicts of Interest: The authors declare that they have no known competing financial interests or personal relationships that could have appeared to influence the work reported in this paper.

\section{References}

1. Wang, L.; Xi, G.; Wan, S.; Zhao, C.; Liu, X. Asymmetrically superhydrophobic cotton fabrics fabricated by mist polymerization of lauryl methacrylate. Cellulose 2014, 21, 2983-2994. [CrossRef]

2. Sasaki, K.; Tenjimbayashi, M.; Manabe, K.; Shiratori, S. Asymmetric superhydrophobic/superhydrophilic cotton fabrics designed by spraying polymer and nanoparticles. ACS Appl. Mater. Interfaces 2015, 8, 651-659. [CrossRef] [PubMed]

3. Periolatto, M.; Ferrero, F.; Montarsolo, A.; Mossotti, R. Hydrorepellent finishing of cotton fabrics by chemically modified TEOS based nanosol. Cellulose 2013, 20, 355-364. [CrossRef]

4. Xu, Z.; Miyazaki, K.; Hori, T. Fabrication of polydopamine-coated superhydrophobic fabrics for oil/water separation and self-cleaning. Appl. Surf. Sci. 2016, 370, 243-251. [CrossRef]

5. Cao, C.; Ge, M.; Huang, J.; Li, S.; Deng, S.; Zhang, S.; Chen, Z.; Zhang, K.; Al-Deyab, S.S.; Lai, Y. Robust fluorine-free superhydrophobic PDMS-ormosil@ fabrics for highly effective self-cleaning and efficient oil-water separation. J. Mater. Chem. A 2016, 4, 12179-12187. [CrossRef]

6. Huang, J.; Li, S.; Ge, M.; Wang, L.; Xing, T.; Chen, G.; Liu, X.; Al-Deyab, S.S.; Zhang, K.; Chen, T. Robust superhydrophobic $\mathrm{TiO}_{2} @$ fabrics for UV shielding, self-cleaning and oil-water separation. J. Mater. Chem. A 2015, 3, 2825-2832. [CrossRef]

7. Liu, Y.; Wang, X.; Fei, B.; Hu, H.; Lai, C.; Xin, J.H. Bioinspired, Stimuli-Responsive, Multifunctional Superhydrophobic Surface with Directional Wetting, Adhesion, and Transport of Water. Adv. Funct. Mater. 2015, 25, 5047-5056. [CrossRef]

8. Alammar, A.; Park, S.H.; Williams, C.J.; Derby, B.; Szekely, G. Oil-in-water separation with graphene-based nanocomposite membranes for produced water treatment. J. Membr. Sci. 2020, 603, 118007. [CrossRef]

9. Li, Z.; Zhong, L.; Zhang, T.; Qiu, F.; Yue, X.; Yang, D. Sustainable, Flexible, and Superhydrophobic Functionalized Cellulose Aerogel for Selective and Versatile Oil/Water Separation. ACS Sustain. Chem. Eng. 2019, 7, 9984-9994. [CrossRef]

10. Shi, G.; Shen, Y.; Mu, P.; Wang, Q.; Yang, Y.; Ma, S.; Li, J. Effective separation of surfactant-stabilized crude oil-in-water emulsions by using waste brick powder-coated membranes under corrosive conditions. Green Chem. 2020, 22, 1345-1352. [CrossRef]

11. Aminayi, P.; Abidi, N. Imparting super hydro/oleophobic properties to cotton fabric by means of molecular and nanoparticles vapor deposition methods. Appl. Surf. Sci. 2013, 287, 223-231. [CrossRef]

12. Li, Y.; Zou, C.; Shao, J.; Li, Y.N. Fabrication of superhydrophobic cotton fabrics through wrapping silica with plasma-induced grafting polymerization. Text. Res. J. 2019, 89, 401-410. [CrossRef] 
13. Xu, L.; Deng, J.; Guo, Y.; Wang, W.; Zhang, R.; Yu, J. Fabrication of super-hydrophobic cotton fabric by low-pressure plasma-enhanced chemical vapor deposition. Text. Res. J. 2019, 89, 1853-1862. [CrossRef]

14. Pan, G.; Xiao, X.; Yu, N.; Ye, Z. Fabrication of superhydrophobic coatings on cotton fabric using ultrasound-assisted in-situ growth method. Prog. Org. Coat. 2018, 125, 463-471. [CrossRef]

15. Yang, M.; Liu, W.; Jiang, C.; He, S.; Xie, Y.; Wang, Z. Fabrication of superhydrophobic cotton fabric with fluorinated $\mathrm{TiO}_{2}$ sol by a green and one-step sol-gel process. Carbohydr. Polym. 2018, 197, 75-82. [CrossRef] [PubMed]

16. Jeyasubramanian, K.; Hikku, G.; Preethi, A.; Benitha, V.; Selvakumar, N. Fabrication of water repellent cotton fabric by coating nano particle impregnated hydrophobic additives and its characterization. J. Ind. Eng. Chem. 2016, 37, 180-189. [CrossRef]

17. Mai, Z.; Shu, X.; Li, G.; Chen, D.; Liu, M.; Xu, W.; Zhang, H. One-step fabrication of flexible, durable and fluorine-free superhydrophobic cotton fabrics for efficient oil/water separation. Cellulose 2019, 26, 6349-6363. [CrossRef]

18. Zhang, M.; Pang, J.; Bao, W.; Zhang, W.; Gao, H.; Wang, C.; Shi, J.; Li, J. Antimicrobial cotton textiles with robust superhydrophobicity via plasma for oily water separation. Appl. Surf. Sci. 2017, 419, 16-23. [CrossRef]

19. Lei, S.; Shi, Z.; Ou, J.; Wang, F.; Xue, M.; Li, W.; Qiao, G.; Guan, X.; Zhang, J. Durable superhydrophobic cotton fabric for oil/water separation. Colloids Surf. A Physicochem. Eng. Asp. 2017, 533, 249-254. [CrossRef]

20. Kong, X.; Zhu, C.; Lv, J.; Zhang, J.; Feng, J. Robust fluorine-free superhydrophobic coating on polyester fabrics by spraying commercial adhesive and hydrophobic fumed $\mathrm{SiO}_{2}$ nanoparticles. Prog. Org. Coat. 2020, 138, 105342. [CrossRef]

21. Yang, J.; Pu, Y.; He, H.; Cao, R.; Miao, D.; Ning, X. Superhydrophobic cotton nonwoven fabrics through atmospheric plasma treatment for applications in self-cleaning and oil-water separation. Cellulose 2019, 26, 7507-7522. [CrossRef]

22. Li, Y.; Zheng, X.; Xia, Z.; Lu, M. Synthesis of fluorinated block copolymer and superhydrophobic cotton fabrics preparation. Prog. Org. Coat. 2016, 97, 122-132. [CrossRef]

23. Deng, B.; Cai, R.; Yu, Y.; Jiang, H.; Wang, C.; Li, J.; Li, L.; Yu, M.; Li, J.; Xie, L. Laundering durability of superhydrophobic cotton fabric. Adv. Mater. 2010, 22, 5473-5477. [CrossRef] [PubMed]

24. Gao, Q.; Hu, J.; Li, R.; Pang, L.; Xing, Z.; Xu, L.; Wang, M.; Guo, X.; Wu, G. Preparation and characterization of superhydrophobic organic-inorganic hybrid cotton fabrics via $\gamma$-radiation-induced graft polymerization. Carbohydr. Polym. 2016, 149, 308-316. [CrossRef]

25. Xi, G.; Fan, W.; Wang, L.; Liu, X.; Endo, T. Fabrication of asymmetrically superhydrophobic cotton fabrics via mist copolymerization of 2, 2, 2-trifluoroethyl methacrylate. J. Polym. Sci. Part A Polym. Chem. 2015, 53, 1862-1871. [CrossRef]

26. Lee, M.; Kwak, G.; Yong, K. Wettability control of ZnO nanoparticles for universal applications. ACS Appl. Mater. Interfaces 2011, 3, 3350-3356. [CrossRef]

27. Afzal, S.; Daoud, W.A.; Langford, S.J. Superhydrophobic and photocatalytic self-cleaning cotton. J. Mater. Chem. A 2014, 2, 18005-18011. [CrossRef]

28. Manatunga, D.C.; de Silva, R.M.; de Silva, K.N. Double layer approach to create durable superhydrophobicity on cotton fabric using nano silica and auxiliary non fluorinated materials. Appl. Surf. Sci. 2016, 360, 777-788. [CrossRef]

29. Richard, E.; Lakshmi, R.; Aruna, S.; Basu, B.J. A simple cost-effective and eco-friendly wet chemical process for the fabrication of superhydrophobic cotton fabrics. Appl. Surf. Sci. 2013, 277, 302-309. [CrossRef]

30. Shi, Y.; Wang, Y.; Feng, X.; Yue, G.; Yang, W. Fabrication of superhydrophobicity on cotton fabric by sol-gel. Appl. Surf. Sci. 2012, 258, 8134-8138. [CrossRef]

31. Liu, F.; Ma, M.; Zang, D.; Gao, Z.; Wang, C. Fabrication of superhydrophobic/superoleophilic cotton for application in the field of water/oil separation. Carbohydr. Polym. 2014, 103, 480-487. [CrossRef] [PubMed]

32. Xu, B.; Cai, Z.; Wang, W.; Ge, F. Preparation of superhydrophobic cotton fabrics based on $\mathrm{SiO}_{2}$ nanoparticles and $\mathrm{ZnO}$ nanorod arrays with subsequent hydrophobic modification. Surf. Coat. Technol. 2010, 204, 1556-1561. [CrossRef]

33. Xu, B.; Cai, Z. Fabrication of a superhydrophobic $\mathrm{ZnO}$ nanorod array film on cotton fabrics via a wet chemical route and hydrophobic modification. Appl. Surf. Sci. 2008, 254, 5899-5904. [CrossRef]

34. Xu, L.; Zhuang, W.; Xu, B.; Cai, Z. Fabrication of superhydrophobic cotton fabrics by silica hydrosol and hydrophobization. Appl. Surf. Sci. 2011, 257, 5491-5498. [CrossRef] 
35. Zhang, M.; Zang, D.; Shi, J.; Gao, Z.; Wang, C.; Li, J. Superhydrophobic cotton textile with robust composite film and flame retardancy. RSC Adv. 2015, 5, 67780-67786. [CrossRef]

36. Ivanova, N.; Zaretskaya, A. Simple treatment of cotton textile to impart high water repellent properties. Appl. Surf. Sci. 2010, 257, 1800-1803. [CrossRef]

37. Wu, M.; Ma, B.; Pan, T.; Chen, S.; Sun, J. Silver-nanoparticle-colored cotton fabrics with tunable colors and durable antibacterial and self-healing superhydrophobic properties. Adv. Funct. Mater. 2016, 26, 569-576. [CrossRef]

38. Pi, P.; Hou, K.; Wen, X.; Xu, S.; Cheng, J.; Xu, G.; Wang, S. A facile one-step fabrication of robust superhydrophobic/superoleophilic cotton fabric using a crosslinkable POSS-containing fluorinated copolymer. Prog. Org. Coat. 2016, 101, 522-529. [CrossRef]

39. Sun, D.; Wang, W.; Yu, D. Highly hydrophobic cotton fabrics prepared with fluorine-free functionalized silsesquioxanes. Cellulose 2017, 24, 4519-4531. [CrossRef]

40. Wei, C.; Tang, Y.; Zhang, G.; Zhang, Q.; Zhan, X.; Chen, F. Facile fabrication of highly omniphobic and self-cleaning surfaces based on water mediated fluorinated nanosilica aggregation. RSC Adv. 2016, 6, 74340-74348. [CrossRef]

41. Meuler, A.J.; Smith, J.D.; Varanasi, K.K.; Mabry, J.M.; McKinley, G.H.; Cohen, R.E. Relationships between water wettability and ice adhesion. ACS Appl. Mater. Interfaces 2010, 2, 3100-3110. [CrossRef] [PubMed]

42. Maciejewski, H.; Karasiewicz, J.; Dutkiewicz, M.; Nowicki, M. Effect of the type of fluorofunctional organosilicon compounds and the method of their application onto the surface on its hydrophobic properties. RSC Adv. 2014, 4, 52668-52675. [CrossRef]

43. Li, Z.; Xing, Y.; Dai, J. Superhydrophobic surfaces prepared from water glass and non-fluorinated alkylsilane on cotton substrates. Appl. Surf. Sci. 2008, 254, 2131-2135. [CrossRef]

44. Muresan, E.I.; Balan, G.; Popescu, V. Durable hydrophobic treatment of cotton fabrics with glycidyl stearate. Ind. Eng. Chem. Res. 2013, 52, 6270-6276. [CrossRef]

45. Britcher, L.G.; Kehoe, D.C.; Matisons, J.G.; Swincer, A.G. Siloxane coupling agents. Macromolecules 1995, 28, 3110-3118. [CrossRef]

46. Sela, Y.; Magdassi, S.; Garti, N. Newly designed polysiloxane-graft-poly (oxyethylene) copolymeric surfactants: Preparation, surface activity and emulsification properties. Colloid Polym. Sci. 1994, 272, 684-691. [CrossRef]

47. Lin, W.; Huang, Y.; Li, J.; Liu, Z.; Yang, W.; Li, R.; Chen, H.; Zhang, X. Preparation of highly hydrophobic and anti-fouling wood using poly (methylhydrogen) siloxane. Cellulose 2018, 25, 7341-7353. [CrossRef]

48. Liu, Z.; Yu, J.; Lin, W.; Yang, W.; Li, R.; Chen, H.; Zhang, X. Facile method for the hydrophobic modification of filter paper for applications in water-oil separation. Surf. Coat. Technol. 2018, 352, 313-319. [CrossRef]

49. Nagappan, S.; Park, S.S.; Kim, B.K.; Yoo, D.; Jo, N.J.; Lee, W.K.; Ha, C.S. Synthesis and functionalisation of mesoporous materials for transparent coating and organic dye adsorption. New J. Chem. 2018, 42, 10254-10262. [CrossRef]

50. Ding, Y.; Jiao, Z.S.; Guo, D.J.; Xiao, S.J.; Tan, W.; Dai, Z.D. Tunable cohesion and water lubrication of PEG-g-PMHS-c-PMVS copolymer membranes. Colloids Surf. A 2012, 395, 199-206. [CrossRef]

51. Poyraz, B.; Tozluolu, A.; Candan, Z.; Demir, A.; Yavuz, M. Influence of PVA and silica on chemical, thermo-mechanical and electrical properties of Celluclast-treated nanofibrillated cellulose composites. Int. J. Biol. Macromol. 2017, 104, 384-392. [CrossRef] [PubMed]

52. Ang, T.N.; Ngoh, G.C.; Chua, A.S.M.; Lee, M.G. Elucidation of the effect of ionic liquid pretreatment on rice husk via structural analyses. Biotechnol. Biofuels 2012, 5, 67. [CrossRef] [PubMed]

53. Ivanova, Y.; Gerganova, T.; Dimitriev, Y.; Salvado, I.M.; Fernandes, M. Nanostructured hybrid materials as precursors for synthesis of nanocoposites in Si-O-C-N-Zr system. Thin Solid Film. 2006, 515, 271-278. [CrossRef]

54. Zhang, X.; Su, W.; Lin, M.; Miao, X.; Ye, L.; Yang, W.; Jiang, B. Non-supercritical drying sol-gel preparation of superhydrophobic aerogel ORMOSIL thin films with controlled refractive index. J. Sol-Gel Sci. Technol. 2015, 74, 594-602. [CrossRef]

55. Soum-Glaude, A.; Thomas, L.; Tomasella, E. Amorphous silicon carbide coatings grown by low frequency PACVD: Structural and mechanical description. Surf. Coat. Technol. 2006, 200, 6425-6429. [CrossRef]

56. El Rassy, H.; Pierre, A. NMR and IR spectroscopy of silica aerogels with different hydrophobic characteristics. J. Non-Cryst. Solids 2005, 351, 1603-1610. [CrossRef] 
57. Han, S.W.; Park, E.J.; Jeong, M.G.; Kim, I.H.; Seo, H.O.; Kim, J.H.; Kim, K.D.; Kim, Y.D. Fabrication of recyclable superhydrophobic cotton fabrics. Appl. Surf. Sci. 2017, 400, 405-412. [CrossRef]

58. Zhang, X.; Xia, B.; Ding, B.; Zhang, Y.; Luo, J.; Jiang, B. Ultra-fast surface hydrophobic modification of sol-gel silica antireflective coating with enhanced abrasion-resistance. Mater. Lett. 2013, 104, 31-33. [CrossRef]

59. Gao, L.; Gan, W.; Xiao, S.; Zhan, X.; Li, J. A robust superhydrophobic antibacterial Ag-TiO 2 composite film immobilized on wood substrate for photodegradation of phenol under visible-light illumination. Ceram. Int. 2016, 42, 2170-2179. [CrossRef]

60. Liu, W.; Xie, T.; Qiu, R. Bamboo fibers grafted with a soybean-oil-based monomer for its unsaturated polyester composites. Cellulose 2016, 23, 2501-2513. [CrossRef]

61. Zhang, X.; Lin, W.; Zheng, J.; Sun, Y.; Xia, B.; Yan, L.; Jiang, B. Insight into the organic-inorganic hybrid and microstructure tailor mechanism of sol-gel ORMOSIL antireflective coatings. J. Phys. Chem. C 2018, 122, 596-603. [CrossRef]

62. Xue, C.H.; Jia, S.T.; Zhang, J.; Tian, L.Q. Superhydrophobic surfaces on cotton textiles by complex coating of silica nanoparticles and hydrophobization. Thin Solid Film. 2009, 517, 4593-4598. [CrossRef]

63. Shirgholami, M.A.; Khalil-Abad, M.S.; Khajavi, R.; Yazdanshenas, M.E. Fabrication of superhydrophobic polymethylsilsesquioxane nanostructures on cotton textiles by a solution-immersion process. J. Colloid Interface Sci. 2011, 359, 530-535. [CrossRef] [PubMed]

64. Lin, W.; Sun, Y.; Zheng, J.; Zheng, Y.; Yan, L.; Jiang, B.; Yang, W.; Chen, H.; Zhang, X. Surface Modification of Sol-Gel Silica Antireflective Coatings by F-PMHS: A Simple Method for Improvement of Amphiphobicity. Coatings 2018, 8, 57. [CrossRef]

(C) 2020 by the authors. Licensee MDPI, Basel, Switzerland. This article is an open access article distributed under the terms and conditions of the Creative Commons Attribution (CC BY) license (http://creativecommons.org/licenses/by/4.0/). 